\title{
Emissão de folhas e início de acumulação de amido em raízes de uma variedade de mandioca em função da época de plantio
}

\author{
Leaf emergence and beginning of starch accumulation in roots of a cassava variety as a function of \\ planting date
}

\author{
Alfredo Schons ${ }^{\mathrm{I}}$ Nereu Augusto Streck ${ }^{\mathrm{II}}$ Bruno Kraulich ${ }^{\mathrm{III}}$ Diego Garrido Pinheiro ${ }^{\mathrm{III}}$ \\ Alencar Junior Zanon ${ }^{\text {III }}$
}

\section{RESUMO}

O número de folhas acumulado (NF) na haste principal está associado com o aparecimento de vários estádios de desenvolvimento da cultura da mandioca. O início de acumulação de amido (IAA) nas raízes tuberosas da mandioca marca o início da translocação dos fotoassimilados para o principal órgão de reserva nessa espécie. O objetivo deste trabalho foi estimar o filocrono e identificar um indicador morfológico baseado no NF para o IAA em mandioca plantada em diferentes épocas. Um experimento a campo foi conduzido em Santa Maria, RS, Brasil, com quatro épocas de plantio (28/09; 11/10; 16/11 e 27/12/2005). A variedade de mandioca usada foi a "RS 13", plantada em baldes de 12 litros, enterrados no espaçamento com $2,0 \times 0,8 \mathrm{~m}$. O delineamento experimental foi o inteiramente casualizado com 11 repetições. A soma térmica diária (STd, ${ }^{\circ} \mathrm{C}$ dia) foi calculada a partir da

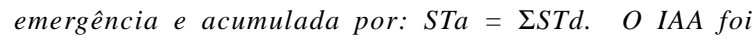
determinado nas plantas de cada balde quando uma raiz atingia um diâmetro de $1 \mathrm{~cm}$. O NF na data do IAA e o número final de folhas (NFF) até o primeiro simpódio também foram determinados. O filocrono variou de 20,3 a $29,5^{\circ} \mathrm{C}$ dia folha ${ }^{-1} e$ seus valores foram maiores quanto mais tardio foi o plantio. $O$ NFF variou entre as épocas de plantio, aumentando com o atraso do plantio. O NF no IAA foi similar nas quatro épocas de plantio e ocorreu quando, em média, o NF corresponde a $20,9( \pm 1,0)$ folhas.

Palavras-chave: Manihot esculenta, aparecimento de folhas, filocrono, temperatura base, RS 13.

\begin{abstract}
The accumulated number of leaves (NF) on the main stem is related to the appearance of several developmental stages in cassava. The beginning of starch accumulation (IAA) in the fibrous roots of cassava switches the source/sink ratio because of the translocation of photoassimilates to the major storage organ in this species. This study was aimed at estimating the phyllochron and identifing a morphological indicator based on NF for IAA in cassava grown in several planting dates. A field experiment was carried out in Santa Maria, RS, Brazil, with four planting dates (28/09, 11/10, 16/11 and 27/12/2005). The variety RS 13 was used and planted in 12 l pots, buried in the soil in a $2.0 \times 0.8 \mathrm{~m}$ spacing. The experimental desing was a completely randomized with 11 replications. Daily degreedays $\left(\mathrm{STd},{ }^{\circ} \mathrm{C}\right.$ day) were calculated starting at emergency and accumulated by STa $=\Sigma S T$. IAA was determined on the plants when one root reached a diameter of $0.01 \mathrm{~m}$. NF on the date of IAA and the main sterm final leaf number (NFF) up to the first sympodial branches were determined. The plyllochron varied from 20.3 to $29.5^{\circ} \mathrm{C}_{\text {day leaf }}^{-1}$, with larger values in the two latest planting dates. The NFF varied among planting dates, increasing as planting was delayed. The NF at IAA was similar for the four planting dates and occurred when NF was on average 20.9 ( \pm 1.0 ) leaves.
\end{abstract}

Key words: Manihot esculenta, leaf appearance, phyllochron, base temperature, RS 13.

'Programa de Pós-graduação em Agronomia, Centro de Ciências Rurais (CCR), Universidade Federal de Santa Maria (UFSM) e Associação Riograndense de Empreendimentos de Assistência Técnica e Extensão Rural (ASCAR-EMATER/RS). E-mail: aschons@emater.tche.br.

"Departamento de Fitotecnia, CCR, UFSM, Avenida Roraima, 1000, 97105-900, Santa Maria, RS, Brasil. E-mail: nstreck1@smail.ufsm.br. Autor para correspondência.

IIICurso de Graduação em Agronomia, CCR, UFSM, Santa Maria, RS, Brasil. 


\section{INTRODUÇÃO}

A mandioca (Manihot esculenta L.Crantz) é uma importante cultura em pequenas propriedades familiares do Sul do Brasil. As raízes são fontes de carboidratos na alimentação humana, sendo as raízes e a parte aérea também usadas na alimentação animal. Devido a isso, pode-se dizer que a cultura da mandioca possui elevada importância social e a pesquisa com essa cultura tem potencial para afetar o bem estar de um considerável número de pessoas de camadas sociais de baixa renda no Brasil.

Entre os fatores ambientais, a temperatura do ar é um dos principais elementos que afetam o desenvolvimento da maioria das espécies vegetais (HODGES, 1991; YAN \& HUNT, 1999; STRECK, 2002a), incluindo a mandioca (MATTHEWS \& HUNT, 1994). Os primeiros estudos relacionando desenvolvimento vegetal com temperatura do ar são creditados a René A. F. de Réamur, que os realizou na França, por volta de 1730. Ele observou que o somatório da temperatura do ar era praticamente constante para completar o ciclo de desenvolvimento de várias espécies em diferentes anos (STRECK, 2002a). Essa constante assumida por Réamur foi chamada de soma térmica, com unidade de ${ }^{\circ} \mathrm{C}$ dia (PEREIRA et al., 2002). Na sua forma mais simples de cálculo, acumulam-se os ${ }^{\circ} \mathrm{C}$ dia acima de uma temperatura base, a qual depende do genótipo, definida como a temperatura abaixo da qual não ocorre desenvolvimento ou o desenvolvimento é tão lento que, para fins de cálculo, pode ser considerado desprezível (BRUNINI et al., 1976; McMASTER \& WILHELM, 1997). A soma térmica é uma medida de tempo biológico que leva em conta o efeito da temperatura nos processos fisiológicos da planta e, assim, é uma medida de tempo mais realística do que o tempo expresso em dias do calendário civil, como, por exemplo, dias após a semeadura ou transplante (GILMORE \& ROGERS, 1958; ARNOLD, 1960; RUSSELE et al., 1984).

Desenvolvimento e crescimento das plantas são processos independentes, que podem ocorrer simultaneamente ou não (WILHELM \& McMASTER, 1995). Desenvolvimento refere-se à diferenciação celular, iniciação e aparecimento de órgãos, e se estende até a senescência da cultura, enquanto que crescimento é o aumento irreversível de uma grandeza física como massa, área, altura, diâmetro e volume (HODGES, 1991; WILHELM \& McMASTER, 1995). Como exemplo de variáveis de desenvolvimento, tem-se a velocidade de emissão de folhas, que, ao ser integrada no tempo, fornece o número de folhas acumuladas na haste principal (NF), a qual é uma excelente medida de desenvolvimento vegetal (STRECK, 2002a; STRECK et al., 2003a). O NF está associado ao aparecimento de vários estádios de desenvolvimento da cultura e à evolução da área foliar da planta, a qual é responsável pela interceptação da radiação solar pelo dossel vegetal, pela fotossíntese e peo rendimento da cultura (STRECK et al., 2003b; XUE et al., 2004; STRECK et al., 2005a,b). Em mandioca, por exemplo, a primeira ramificação simpodial ocorre após um determinado NF da haste principal (MATTHEWS \& HUNT, 1994). O NF pode ser medido diretamente na planta a campo, ou estimado usando-se o conceito do filocrono, definido como o intervalo de tempo entre o aparecimento de duas folhas sucessivas na haste (KLEPPER et al. 1982; WILHELM \& McMASTER, 1995; STRECK et al., 2005a,b). Usandose a soma térmica como medida de tempo em plantas, o filocrono tem unidade ${ }^{\circ} \mathrm{C}$ dia folha ${ }^{-1}$.

O início de acumulação de amido (IAA) nas raízes tuberosas é um estádio de desenvolvimento importante durante o ciclo da mandioca, pois marca o início da translocação dos fotoassimilados para o principal órgão de reserva dessa espécie, modificando a partir de então a relação fonte/dreno na planta (MATTHEWS \& HUNT, 1994). Quando ocorre alteração na relação fonte/dreno da planta, práticas de manejo devem ser realizadas para manter o potencial de rendimento da cultura. Nesse caso, a identificação do IAA é importante no manejo da cultura da mandioca, como, por exemplo, a adubação nitrogenada de cobertura, já que a demanda de nitrogênio aumenta a partir desse estádio de desenvolvimento.

No entanto, a identificação do IAA a campo é difícil, exigindo o arranquio da planta. Para contornar esta dificuldade, busca-se um indicador morfológico mais visível ao observador. Em batata, o início de acumulação de amido está relacionado com o NF na haste principal (PAULA et al., 2005). Porém, em mandioca, uma consulta na literatura revelou que ainda não foi quantificada a relação entre IAA e NF na haste principal, o que constitui uma justificativa para esse esforço científico. Oportuno, e também um tema contínuo de pesquisa, é caracterizar o crescimento e o desenvolvimento de genótipos em diferentes épocas de plantio, especialmente quando a cultura é pouco estudada, como é o caso da mandioca no Rio Grande do Sul.

No presente trabalho, teve-se por objetivo estimar o filocrono e identificar um indicador morfológico baseado no número de folhas acumuladas na haste principal para o início de acumulação de amido em mandioca cultivada em diferentes épocas de plantio. 


\section{MATERIAL E MÉTODOS}

Um experimento em campo foi conduzido na área experimental do Departamento de Fitotecnia da Universidade Federal de Santa Maria, Santa Maria, RS, Brasil (latitude: $29^{\circ} 43^{\prime} \mathrm{S}$; longitude: $53^{\circ} 43^{\prime} \mathrm{W}$; altitude 95m) O clima do local, segundo a classificação de Köppen, é do tipo Cfa, subtropical úmido com verões quentes e sem estação seca definida (MORENO, 1961). O experimento consistiu de quatro épocas de plantio da mandioca: 28/09/2005, 11/10/2005, 16/11/2005 e $27 /$ 12/2005. Utilizou-se a variedade "RS 13", da Fundação Estadual de Pesquisa Agropecuária do Rio Grande do Sul (FEPAGRO/RS), que é um genótipo de ciclo médio adaptado e bastante usado no Rio Grande do Sul.

O plantio e a condução das plantas foram em baldes plásticos pretos com capacidade de 12 litros. Os baldes foram enterrados no solo visando a minimizar a absorção da radiação solar pelas paredes externas dos mesmos, o que poderia elevar a temperatura do substrato acima da temperatura do solo da área experimental e afetar a taxa de desenvolvimento das plantas. Foram usados onze baldes em cada época, dispostos em linha no espaçamento de $0,8 \mathrm{~m}$ entre baldes. Entre as épocas, as fileiras de baldes foram distanciadas 2,0m. Os baldes foram preenchidos com substrato comercial "PLANTIMAX". Obtou-se em usar substrato para se ter um melhor controle experimental, pois o solo poderia apresentar variabilidade de local para outro, e também para facilitar a determinação do início da acumulação de amido. Com esse procedimento, aumentou a certeza de que a época de plantio foi o único fator a afetar o crescimento e desenvolvimento das plantas.

A adubação de plantio nos baldes foi correspondente a $250 \mathrm{~kg} \mathrm{ha}^{-1}$ da fórmula 05-20-20 e a duas adubações de cobertura com $50 \mathrm{~kg} \mathrm{ha}^{-1}$ de uréia aos 50 e 75 dias após a emergência, respectivamente. Houve complementações de irrigação por aspersão sempre que necessário para manter as plantas em crescimento e desenvolvimento sem deficiência hídrica.

Foram plantadas duas manivas de $0,2 \mathrm{~m}$ de comprimento em cada balde. A emergência (EM) das plantas foi considerada quando $50 \%$ das plantas estavam visíveis acima do solo. O delineamento experimental foi o inteiramente casualizado, com 11 repetições (balde com duas manivas). Duas plantas por balde (uma oriunda de cada maniva) foram identificadas com arames coloridos logo após a emergência. Na haste principal das plantas etiquetadas, foi realizada a contagem do número de folhas (NF) na haste principal, uma vez por semana, até o surgimento da primeira ramificação simpodial. Uma folha foi considerada visível quando as bordas de um dos lóbulos da folha não mais se tocavam.

O início do acúmulo de amido (IAA) foi considerado quando uma raiz tuberosa da planta apresentou um diâmetro de $0,01 \mathrm{~m}$. Para a determinação do IAA, as plantas foram retiradas dos baldes quando apresentavam aproximadamente 20 folhas. Nesse momento, foi medido o diâmetro da maior raiz tuberosa de cada planta com um paquímetro. Em função das raízes das plantas amostradas apresentarem diâmetros variáveis pouco maiores ou menores do que $0,01 \mathrm{~m}$, o NF no IAA de cada planta foi então estimado por regra de três simples (determinação da quarta proporcional) para um diâmetro de raiz de $0,01 \mathrm{~m}$. Após a avaliação do IAA, as plantas foram replantadas para o mesmo balde e prosseguiram seu crescimento. O número final de folhas (NFF) até a primeira ramificação simpodial também foi registrado na haste principal das 22 plantas etiquetadas em cada época de plantio.

Os valores diários de temperatura mínima e máxima do ar durante o período experimental foram coletados na Estação Climatológica Principal pertencente ao $8^{\circ}$ Distrito de Meteorologia, localizada a aproximadamente $150 \mathrm{~m}$ da área experimental.

A soma térmica diária $\left(\mathrm{STd},{ }^{\circ} \mathrm{C}\right.$ dia) foi calculada por (ARNOLD, 1960):

$\mathrm{STd}=[(\mathrm{TM}+\mathrm{Tm}) / 2]-\mathrm{Tb} \cdot 1$ dia $\quad$ (Equação 1)

Em que TM é a temperatura máxima diária do ar $\left({ }^{\circ} \mathrm{C}\right)$, Tm é a temperatura mínima diária do ar e $\mathrm{Tb}$ é a temperatura basal mínima ou temperatura base (Tb) da cultura $\left({ }^{\circ} \mathrm{C}\right)$.

A soma térmica acumulada (STa, ${ }^{\circ} \mathrm{C}$ dia) a partir da emergência foi calculada por:

$\mathrm{STa}=\Sigma \mathrm{STd}$

(Equação 2)

Como o genótipo usado nesse estudo é uma variedade desenvolvida no Rio Grande do Sul e não se conhece o valor da $\mathrm{Tb}$ para essa variedade, estimou-se a Tb usada na equação (1) através da metodologia usada em SINCLAIR et al. (2004) usando-se os dados de NF coletados nos plantios realizados em 28/09/2005 e 11/10/2005. Não foram utilizados os dados das duas outras épocas de plantio (16/11/2005 e 27/12/2005), pois, na metodologia de estimativa da $\mathrm{Tb}$, deve-se ter a planta emitindo folhas quando ocorrem temperaturas amenas e próximas da Tb (SINCLAIR et al., 2004), o que só aconteceu nas duas primeiras épocas de plantio. $\mathrm{Na}$ estimativa da $\mathrm{Tb}$, foi utilizada a metodologia do menor quadrado médio do erro (QME) da regressão entre o NF e a STa a partir da emergência (SINCLAIR et al., 
2004). Foram estimadas equações de regressão linear simples para os valores do NF em função da STa nas duas épocas de plantio, assumindo-se vários valores de $\mathrm{Tb}$ variando de zero a $20^{\circ} \mathrm{C}$, com incremento de $1^{\circ} \mathrm{C}$. Foi plotado num gráfico o QME em função da Tb, e o valor da $\mathrm{Tb}$ foi considerado como o valor que resultou no menor QME (SINCLAIR et al., 2004).

Para estimativa do filocrono, obteve-se para cada unidade experimental (balde com duas plantas) uma equação de regressão linear simples entre o NF e a STa utilizando-se a Tb estimada. Foram usados os dados de NF até o dia da amostragem das plantas para IAA para eliminar a possibilidade de interferência do arranquio das plantas na taxa de aparecimento de folhas. O filocrono foi estimado como sendo o inverso do coeficiente angular da regressão linear (KLEPPER et al., 1982; STRECK et al., 2005a,b; PAULA et al., 2005).

O rendimento final de raízes por planta foi obtido colhendo-se as quatro épocas em 13/06/2006, quando as plantas de todos os tratamentos estavam em repouso invernal. Realizou-se a determinação do número de raízes tuberosas (maiores que $0,01 \mathrm{~m}$ de diâmetro) por planta e da massa fresca dessas raízes. Depois, as raízes foram colocadas em estufa a $60^{\circ} \mathrm{C}$ até massa constante, para se obter a sua massa seca. Os dados foram submetidos à análise de variância e as médias das variáveis nas épocas de plantio foram distinguidas pelo teste de Tukey a 5\% de probabilidade de erro.

\section{RESULTADOS E DISCUSSÃO}

As quatro épocas de plantio proporcionaram às plantas condições meteorológicas distintas durante o seu ciclo de crescimento e desenvolvimento. Por exemplo, as temperaturas médias do ar durante a fase EM - IAA foram de $21,7^{\circ} \mathrm{C} ; 22,2^{\circ} \mathrm{C}$; $25,6^{\circ} \mathrm{C}$ e $25,8^{\circ} \mathrm{C}$, e os fotoperíodos no dia da emergência foram de 13,7h; 14,1h; 14,8h e 14,8h, respectivamente, para os plantios realizados em 28/09/2005, 11/10/2005, 16/11/2005 e 27/12/2005. Essas condições meteorológicas distintas são importantes em estudos bioclimáticos para a cultura da mandioca, objeto deste trabalho.

$\mathrm{Na}$ figura 1a, está plotada a variação do QME das várias equações de regressão linear entre NF e STa nas duas épocas de plantio, para os diferentes valores de $\mathrm{Tb}$ assumidos. O menor valor do $\mathrm{QME}$ $(0,317706)$ e $(0,245641)$ foi para a $\mathrm{Tb}$ de $15^{\circ} \mathrm{C}$ e $14^{\circ} \mathrm{C}$, respectivamente para os plantios de 28/09/2005 e 11/ 10/2005. MATTHEWS \& HUNT (1994), descrevendo um modelo de crescimento para mandioca no Canadá, usaram uma $\mathrm{Tb}=13^{\circ} \mathrm{C}$ para emissão de folhas e BRAGA et al. (2006) usaram uma $\mathrm{Tb}=15^{\circ} \mathrm{C}$ no zoneamento agrícola de riscos climáticos para a cultura da mandioca para o Estado de Santa Catarina. No presente trabalho, há forte indicativo de que a Tb para aparecimento de folhas desta variedade seja $14^{\circ} \mathrm{C}$, pois, embora no plantio de 28/09/2005 o menor QME tenha sido na $\mathrm{Tb}$ de $15^{\circ} \mathrm{C}$, no plantio de 11/10/2005 o QME para Tb de $14^{\circ} \mathrm{C}$ foi similar (Figura 1a). Assim, adotou-se uma $\mathrm{Tb}=14^{\circ} \mathrm{C}$ para aparecimento de folhas da variedade de mandioca "RS 13" nas análises seguintes deste estudo.

Todas as equações de regressão linear entre $\mathrm{NF}$ e STa, considerando-se uma $\mathrm{Tb}=14^{\circ} \mathrm{C}$, usadas na estimativa do filocrono da mandioca apresentaram valores do coeficiente de determinação $\left(\mathrm{r}^{2}\right)$ de 0,99 em todas as épocas. Como foram realizadas 44 equações de regressão, apenas um exemplo dessas regressões lineares é apresentado na figura $1 \mathrm{~b}$ a título de ilustração, correspondendo a uma repetição da época de plantio de 11/10/2005. Essa linearidade e elevado $r^{2}$ da relação entre o NF e STa indica que a temperatura do ar é o principal fator ecológico que governa o aparecimento de folhas nessa variedade de mandioca e a estimativa do filocrono pelo método da regressão linear entre NF e STa é uma metodologia apropriada. Para a repetição apresentada na Figura 1b, o coeficiente angular foi de 0,0488 folha $\left({ }^{\circ} \mathrm{C} \mathrm{dia}\right)^{-1}$, e seu inverso, o filocrono, foi de $20,5^{\circ} \mathrm{C}$ dia folha ${ }^{-1}$.

O filocrono variou entre as épocas de plantio (Tabela 1). Os menores valores de filocrono (22,1 e $20,3^{\circ} \mathrm{C}$ dia folha $^{-1}$ ) foram obtidos nos dois plantios de 28/09/2005 e 11/10/2005 e não diferiram estatisticamente entre si. Os maiores valores de filocrono $\left(29,3\right.$ a $29,5^{\circ} \mathrm{C}$ dia folha ${ }^{-1}$ ) foram obtidos nos dois plantios de 16/11/ 2005 e 27/12/2005, os quais não diferiram entre si, mas diferiram dos dois anteriores. $\mathrm{O}$ aumento do filocrono com o atraso na época de plantio a partir da primavera para um mesmo genótipo também foram relatados para outras culturas como batata (PAULA et al., 2005) e trigo de primavera (McMASTER \& WILHELM, 1995). Uma das hipóteses para explicar a diferença de filocrono da mandioca entre as épocas de plantio é a temperatura do ar. CAO \& TIBBITS (1995) e PAULA et al.(2005) encontraram aumento do filocrono em batata com o aumento da temperatura do ar. No presente estudo, também houve uma tendência elevada $\left(\mathrm{r}^{2}=0,81\right)$ de aumento do filocrono com o aumento da temperatura do ar (Figura 1c). Para PAULA et al. (2005), a resposta do filocrono ao aumento da temperatura do ar talvez seja resultado da relação linear entre emissão de folhas e temperatura do ar, assumida no cálculo da unidade de tempo (soma térmica) do filocrono. A resposta da emissão de folhas à temperatura é não-linear (STRECK 

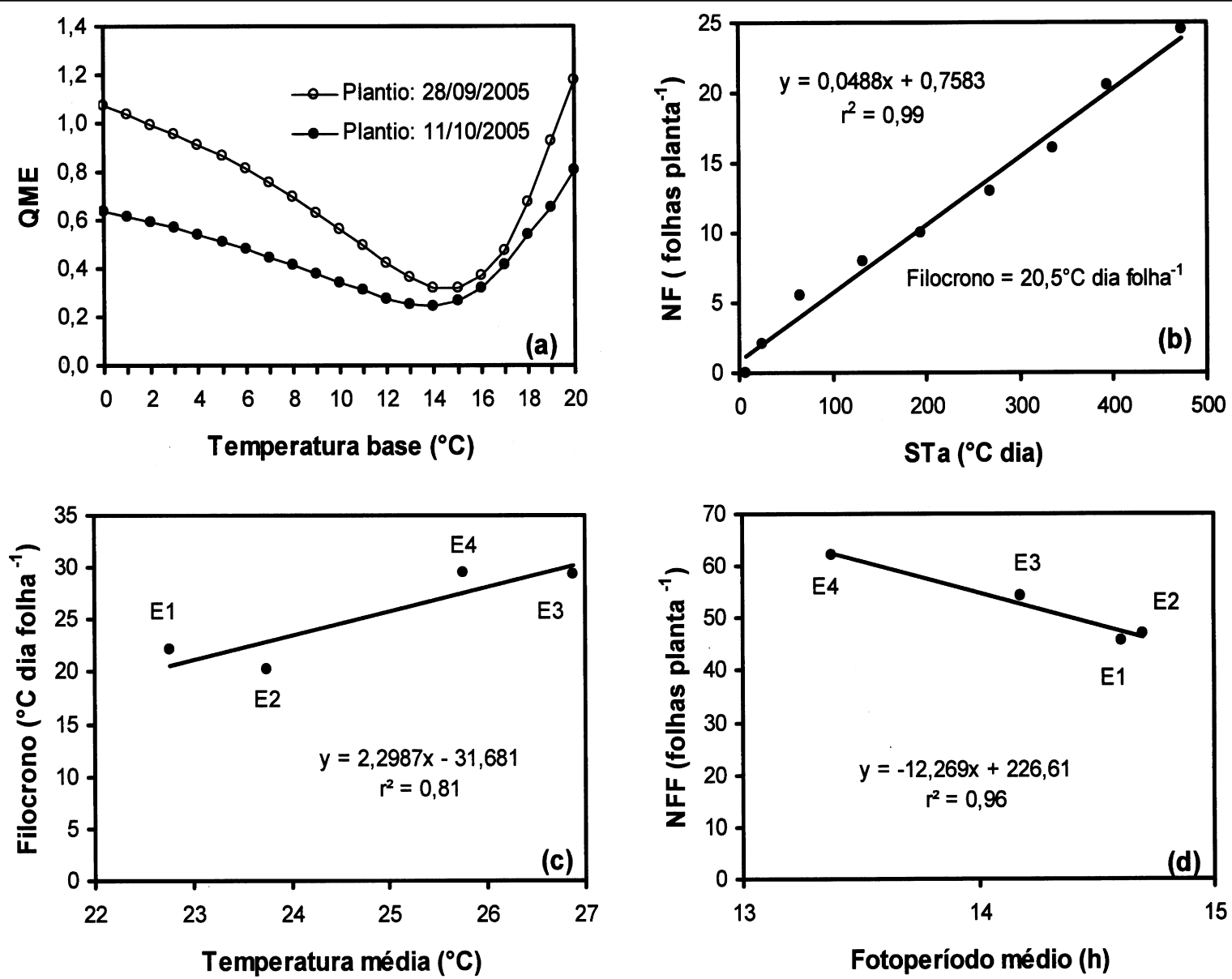

Figura 1 - Quadrado médio do erro (QME) da regressão linear entre o número de folhas (NF) acumuladas na haste principal e a soma térmica acumulada (STa) a partir da emergência, utilizando-se várias temperaturas-base em duas épocas de plantio (a), relação entre NF e STa utilizada na estimativa do filocrono de uma repetição (balde com duas plantas) plantada em 11/10/2005 (b), relação entre filocrono e média da temperatura média diária do ar durante a fase emergência (EM) até o último NF usado na estimativa do filocrono (c) e relação entre número final de folhas na haste principal (NFF) e fotoperíodo médio durante a fase EM até o aparecimento da última folha antes da primeira ramificação simpodial (d) da variedade de mandioca, "RS 13" plantada em quatro épocas (E1 = 28/09/2005, E2 = 11/ 10/2005, E3 = 16/11/2005, E4 = 27/12/2005). Santa Maria, RS, 20005/2006.

et al., 2003a; XUE et al., 2004), de modo que a relação linear pode ser fonte de erro de cálculo na soma térmica, especialmente próximo das temperaturas cardinais (STRECK, 2002a,b, 2004).

Uma outra hipótese que poderia explicar a diferença de filocrono entre as épocas de plantio da mandioca seria o fotoperíodo, já que a taxa de emissão de algumas espécies, como, por exemplo, o trigo, é afetada pelo fotoperíodo (STRECK et al., 2003a). Essa hipótese não se confirmou para a variedade de mandioca "RS 13" usada aqui, pois não houve relação do filocrono com o fotoperíodo médio durante a emissão de folhas (dados não apresentados), o que concorda com a pressuposição usada no modelo de MATTHEWS \& HUNT (1994) de que a taxa de emissão de folhas em mandioca não é afetada pelo fotoperíodo.
O NFF variou entre as épocas de plantio, com uma tendência de aumento do NFF nos plantios tardios (Tabela 1). No entanto, não houve diferença estatística entre as três primeiras épocas que variaram de 45,5 a 54,1 folhas. Já o NFF na quarta época (62 folhas) não foi estatisticamente diferente ao da terceira época e foi estatisticamente superior ao da primeira e segunda épocas. A hipótese para explicar o aumento do NFF com o atraso da época de plantio da variedade de mandioca "RS 13" é o fotoperíodo. Houve uma relação forte $\left(\mathrm{r}^{2}=0,96\right)$ entre NFF e fotoperíodo médio do período entre a emergência e o aparecimento da última folha antes da primeira ramificação simpodial (Figura 1d). Segundo MATTHEWS \& HUNT (1994), o fotoperíodo afeta a taxa de desenvolvimento da mandioca no sentido de que um aumento do 
Tabela 1 - Data (dia/mês/ano) de plantio e de emergência, número de dias entre o plantio e a colheita (Período), filocrono, número final de folhas (NFF) na haste principal até a primeira ramificação simpodial e número de folhas (NF) na haste prinçipal no início da acumulação de amido (IAA) da variedade de mandioca “RS 13”. Santa Maria, RS, Brasil, 2005/2006.

\begin{tabular}{|c|c|c|c|c|c|}
\hline Data de plantio & Data de emergência & Período ( $\mathrm{N}^{\circ}$ de dias) & Filocrono $\left({ }^{\circ} \mathrm{C}\right.$ dia folha $\left.{ }^{-1}\right)$ & NFF (folhas planta ${ }^{-1}$ ) & NF no IAA \\
\hline $28 / 09 / 2005$ & $14 / 10 / 05$ & 257 & $22,1 \mathrm{~b}$ & $45,5 \mathrm{~b}$ & $19,9 \mathrm{a}$ \\
\hline $11 / 10 / 2005$ & $25 / 10 / 05$ & 245 & $20,3 \mathrm{~b}$ & $47,1 \mathrm{~b}$ & $20,6 \mathrm{a}$ \\
\hline $16 / 11 / 2005$ & 29/11/05 & 209 & 29,3 a & $54,1 \mathrm{ab}$ & $21,0 \mathrm{a}$ \\
\hline $27 / 12 / 2005$ & $10 / 01 / 06$ & 168 & 29,5 a & $62,0 \mathrm{a}$ & 21,9 a \\
\hline $\mathrm{CV}(\%)$ & & & 7,46 & 11,89 & 13,54 \\
\hline
\end{tabular}

Médias seguidas pela mesma letra na vertical não diferem entre si pelo teste de Tukey a 5\% de probabilidade de erro. CV = Coeficiente de variação.

fotoperíodo reduz o tempo necessário para aparecerem as ramificações simpodiais. Esse fato caracteriza a mandioca como uma planta de dia longo. A redução do tempo para a primeira ramificação está associada com a redução do NFF até essa ramificação (MATTHEWS \& HUNT, 1994). A relação linear negativa entre NFF e fotoperíodo obtida neste estudo (Figura 1d) é típica de planta de dia longo, confirmando resultados de MATTHEWS \& HUNT (1994).

O NF no IAA foi similar, sem diferença estatística, entre as quatro épocas de plantio (Tabela 1). A implicação desses resultados é a de que se pode estimar facilmente a campo esse importante estádio de desenvolvimento, independentemente da época de plantio. Pelos resultados da tabela 1 , o IAA da variedade de mandioca "RS 13 ” ocorre quando o $\mathrm{NF}=20,9( \pm 1,0)$ folhas.

Os componentes do rendimento da mandioca "RS 13” foram afetados pela época de plantio (Tabela 2). As duas primeiras épocas tiveram o maior número de raízes por planta e a maior massa fresca e seca de raízes por planta e não diferiram estatisticamente da terceira época. O plantio mais tardio (27/12/2005) reduziu drasticamente os componentes do rendimento, sendo que cada planta produziu em média apenas três raízes. Esses resultados reforçam a necessidade de plantio da mandioca na época recomendada para o Rio Grande do Sul, que é de setembro a novembro (WESTPHALEN \& MALUF, 1984). Os rendimentos da massa fresca de raízes, obtidos nas três primeiras épocas, apresentados na tabela 2, transformados para t ha $^{-1}$, considerando-se uma densidade de 16.000 plantas ha $^{-1}$, recomendada para a cultura da mandioca, foram similares ou superiores aos rendimentos de outras variedades de mandioca em outras regiões do Brasil relatados por diversos autores (MATTOS et al., 1985; MATTHEWS \& HUNT, 1994; BORGES et al., 2002; GABRIEL FILHO et al., 2003). Esses resultados indicam que, embora as plantas de mandioca tenham sido cultivadas em baldes neste experimento, certamente não houve prejuízos para o crescimento das plantas pela restrição de espaço ao sistema radicular.

\section{CONCLUSÕES}

A temperatura-base de aparecimento de folhas para a variedade de mandioca “RS13” é de $14^{\circ} \mathrm{C}$. $\mathrm{O}$ filocrono dessa variedade de mandioca varia com essas épocas de plantio, de 20,3 a $29,5^{\circ} \mathrm{C}$ dia folha ${ }^{-1}$. O início de acumulação de amido na mandioca variedade RS 13 pode ser identificado quando na haste principal existem 21 folhas visíveis, independente da época de plantio.

Tabela 2 - Número $\left(\mathrm{n}^{\circ}\right)$ de raízes, massa fresca de raízes tuberosas e massa seca de raízes tuberosas por planta de mandioca, variedade "RS 13”, plantada em quatro épocas. Santa Maria, RS, Brasil, 2005/2006.

\begin{tabular}{|c|c|c|c|}
\hline Data de plantio & Número de raízes $\left(n^{\circ}\right.$ planta $\left.^{-1}\right)$ & Massa fresca (g planta ${ }^{-1}$ ) & Massa seca (g planta ${ }^{-1}$ ) \\
\hline $28 / 09 / 2005$ & $11,6 \mathrm{a}$ & $2326,3 \mathrm{a}$ & $1597,5 \mathrm{a}$ \\
\hline $11 / 10 / 2005$ & 10,9 a & $2323,7 \mathrm{a}$ & 1792,7 a \\
\hline $16 / 11 / 2005$ & 9,8 a & 2101,8 a & 1461,5 a \\
\hline $27 / 12 / 2005$ & $3,0 \mathrm{~b}$ & $485,7 \mathrm{~b}$ & $253,0 \mathrm{~b}$ \\
\hline CV (\%) & 32,93 & 28,73 & 28,61 \\
\hline
\end{tabular}

Médias seguidas pela mesma letra na vertical não diferem entre si pelo teste de Tukey a 5\% de probabilidade de erro. CV = Coeficiente de variação.

Ciência Rural, v.37, n.6, nov-dez, 2007. 


\section{AGRADECIMENTOS}

Alfredo Schons agradece à ASCAR-EMATER/RS pela sua liberação para realizar este estudo como parte do seu programa de Mestrado na UFSM. Nereu Augusto Streck agradece ao $\mathrm{CNPq}$ pela bolsa de Produtividade em Pesquisa. Os autores agradecem a Zeferino Chielle, da FEPAGRO/RS, pelas manivassemente.

\section{REFERÊNCIAS}

ARNOLD, C.Y. Maximum-minimum temperatures as a basis for computing heat units. Proceedings of the American Society for Horticultural Sciences, Boston, v.76, p.682692, 1960.

BORGES, M.F. et al. Avaliação de variedades de mandioca. Pesquisa Agropecuária Brasileira, Brasília, v.37, n.11, p.1559-1565, 2002.

BRAGA, H.J. et al. Zoneamento agrícola considerando os riscos climáticos para a cultura da mandioca (Manihot esculenta Crantz). CIRAM/EPAGRI-SC. Capturado em 24 abr. 2006. On-line. Disponível na Internet http:// ciram.epagri.rtc-sc.br:8080/cms/zoneamento/culturas/ mandioca.jsp.

BRUNINI, O. et al. Temperatura base para alface "White Boston”, em um sistema de unidades térmicas. Bragantia, Campinas, v.35, p.214-219, 1976.

CAO, W.; TIBBITTS, T.W. Leaf emergence on potato stems in relation to thermal time. Agronomy Journal, Madison, v.87, p.474-477, 1995.

GABRIEL FILHO, A.G. et al. Profundidade e espaçamento da mandioca no plantio direto na palha. Ciência Rural, Santa Maria, v.33, n.3, p.461-467, 2003.

GILMORE, E.C.; ROGERS, J.S. Heat units as a method of measuring maturity in corn. Agronomy Journal, Madison, v.50, n.10, p.611-615, 1958.

HODGES, T.F. Predict crop phenology. Boca Raton: CRC, 1991. 233p.

KLEPPER, B. et al. Quantitative characterization of vegetative development in small cereals. Agronomy Journal, Madison, v.74, n.5, p.789-792, 1982.

MATTHEWS, R.B.; HUNT, L.A. GUMCAS: a model describing the growth of cassava (Manihot esculenta L. Crantz). Field Crops Research, Amsterdam, v.36, p.69-84, 1994.

MATTOS, P.L.P.de et al. Mandioca consorciada com milho. Revista Brasileira da Mandioca, Cruz das Almas, v.4, n.2, p.61-67, 1985.

McMASTER, G.S.; WILHELLM, W.W. Accuracy of equations predicting the phyllochron of wheat. Crop Science, Madison, v.35. n.1, p.30-36, 1995.

McMASTER, G.S.; WILHELLM, W.W. Growing degree-days: one equation, two interpretations. Agricultural and Forest Meteorology, Amsterdam, v.87, n.4, p.291-300, 1997.
MORENO, J.A. Clima do Rio Grande do Sul. Porto Alegre: Secretaria de Agricultura, Diretoria de Terras e Colonização, Secção de Geografia, 1961. 43p.

PAULA, F.L.M. et al. Filocrono da planta de batata cultivar Asterix em diferentes épocas de plantio. Revista Brasileira de Agrometeorologia, Santa Maria, v.13, n.3, p.367-374, 2005.

PEREIRA, A.R. et al. Agrometeorologia: fundamentos e aplicação prática. Guaíba: Agropecuária, 2002. 478p.

RUSSELE, M.P. et al. Growth analysis based on degree days. Crop Science, Madison, v.24, n.1, p.28-32, 1984.

SINCLAIR, T.R. et al. Sugarcane leaf area development under field conditions in Florida, USA. Field Crops Research, Amsterdam, v.88, p.171-178, 2004.

STRECK, N.A. A generalized non linear air temperature response function for node appearance rate in muskmelo (Cucumis melo L.). Revista Brasileira de Agrometeorologia, Santa Maria, v.10, n.1, p.105-111, 2002a.

STRECK, N.A. A generalized vernalization response function for lily (Lilium spp.). Revista Brasileira de Agrometeorologia, Santa Maria, v.10, n.2, p.221-228, 2002b.

STRECK, N.A. et al. Incorporating a chronology response into the prediction of leaf appearance rate in winter wheat. Annals of Botany, Oxford, v.92, n.2, p.181-190, 2003a.

STRECK, N.A. et al. Improving predictions of developmental stages in winter wheat: A modified Wang and Ergel model. Agricultural and Forest Meteorology, Amsterdam, v.115, n.3-4, p.139-150, 2003b.

STRECK, N.A. A temperature response function for modeling leaf growth and development of the African violet (Saintpaulia ionantha Wendl.). Ciência Rural, Santa Maria, v.34, n.1, p.55-62, 2004.

STRECK, N.A. et al. Estimativa do filocrono em cultivares de trigo de primavera. Revista Brasileira de Agrometeorologia, Santa Maria, v.13, n.3, p.423-429, $2005 a$.

STRECK, N.A. et al. Estimating leaf appearance rate and phyllochron in safflower (Carthamus tinctorius L.). Ciência Rural, Santa Maria, v.35, n.6, p.1448-1450, 2005b.

XUE, Q. et al. Predicting leaf appearance in field-grown winter wheat: evaluating linear and non-linear models. Ecological Modelling, Amsterdam, v.175, p.261-270, 2004.

WESTPHALEN, S.L.; MALUF, J.R.T. Zoneamento para a mandioca no Rio Grande do Sul. In: INSTITUTO DE PESQUISA AGROPECUÁRIA. IPAGRO Informa. Porto Alegre: CORAG, 1984. p.5-8.

WILHELM, W.W.; McMASTER, G.S. Importance of the phyllochron in studying development and growth in grasses. Crop Science, Madison, v.35, n.1, p.1-3, 1995.

YAN, W.; HUNT, L.A. An equation for modeling the temperature response of plants using only the cardinal temperatures. Annals of Botany, Oxford, v.84, n.5, p.607614, 1999. 